\title{
Editorial
}

\section{Ethical challenges in the pharmaceutical industry}

The conflicts of interest involving physicians, in relationships with the pharmaceutical industry, in the past ten years have known extraordinary regulatory activity. The American College of Physicians and the Accreditation Council for Continuing Medical Education issued guidelines regarding physicians' interactions with drug companies. The Pharmaceutical Research and Manufacturers of America, adopted a broad Code of conduct. In the same line the Office of the Inspector General of the Department of Health and Human Services released a set of guidelines with which manufacturers were urged to comply in order to guard against the risk of liability. A body of federal law dealing with "fraud and abuse" is being used by prosecutors to punish pharmaceutical companies and physicians involved in marketing.

There are a growing realization, of the troubling influence that pharmaceutical marketing can have on patient care. The Medicare program "The prescription-drug benefit", shows a widespread concern about the costs and the reaction of federal prosecutors for increase public expenditures. Thus, the law has begun to annex terrain previously controlled by professional ethic. These changes place new ways in which federal fraud-and-abuse law is being used, and the effect of those changes on relationships between physicians and pharmaceutical companies indicate that the trend will likely be intensified.

Drug liabilities become more frequent, more publicized, and more costly. They impact patients' perception, physicians' practice, clinical research, and medical communication.

Thorough review of the literature and newspapers indicates that the perception of ethical issues in the pharmaceutical industry is largely negative and highlights the scrutiny placed on pharmaceutical companies.

The most prominent issues reported are drug safety, pricing, data disclosure, importation, clinical study design, marketing restrictions, DTC advertising, animal testing, international market, developing countries, issues related to vaccines, growth of drug counterfeiting, the cost effectiveness of treatments, and in the last ten years the Pharmaceutical fraud.

Although individuals and most governments alike see health as a priority and access to health as a right, $80 \%$ of the world population has no or very little access to medicine.

Pharmaceutical companies are often the focal point of hostility because they are one of the most well-known components of healthcare delivery. Other components of health care delivery are payers, policy makers and providers, like doctors and hospitals, who have also been accused in the literature of ethical transgressions. 
From one perspective, the pharmaceutical industry is a vital industry not only because of its economic significance but also because of its impact on the health and well-being of people of all ages and economic levels.

Drug safety emerged as a predominant issue. Includes concerns about the comprehensiveness of reporting of all side effects observed during a clinical study. This issue dominated the newspapers; undoubtedly tied to allegations about Vioxx, Bextra and related drugs. This issue has important ethical consequences because it suggests deception and lack of integrity, conflict of interest, and lack of ethical responsibility to the patient as stakeholder to provide a sound product.

Concerns about drug pricing have been covered extensively in the literature and newspapers. The pricing issue raises questions about sound management regarding meaningful R\&D costs and the public perception of wasteful advertising. Thus, the ethical concern of just prices for drugs is of prime importance.

Data disclosure it is other frequently identified issue. Some articles called for enforcement of a mandatory national drug registry of clinical trials. Another area of attention in the literature concerns clinical data, the link between science and business. Clinical data must support the approval for sale of new drugs.

Another issue is patent exclusivity and the opposition of pharmaceutical companies to any actions that could make additional sources of product available before patent expiration, resulting in restricted patient access to drugs.

Importation/reimportation, focuses on importing or reimporting drugs, primarily from Canada. It is one attempt to circumvent the high price of drugs. Efforts to legalize reimportation or circumvent the existing ban are commonly reported. The clamour for legislation to permit Americans to buy lower-cost prescription drugs from Canada will grow.

When pursuing clinical research, companies have to comply with a number of ethical concepts and standards including the protection of the people involved in the study as well as a commitment to scientific objectivity.

Objectivity has to be ensured when conducting clinical trials. The attention given to the design of the clinical trial is a step in the right direction and so is the suitable payment of research participants.

Further to the issues mentioned above, the context of paediatric medicine is even more sensitive and prone to issues of ethics.

Recently appear new challenges. The pharmaceutical industry has to be very transparent in the way it conducts genetic research, as well as on the implications that this type of research has and alleviating fears about the potential misuse of genetic information and data.

Once a drug is developed, it needs to be marketed and needs to be prescribed. The main issue is the price and the interactions that the company can have with the governments in order to set the levels of reimbursement, coverage etc.

Sales and marketing practices in the industry are areas of potential ethical transgression such as providing gifts or incentives to physicians, promotion of drug benefits 
or off-label use of an approved drug. As primary interfaces between pharmaceutical companies and patients, physicians are the target of marketing and sales efforts. These marketing and sales practices are costly and can add up to more than what some companies spent on R\&D.

DTC advertising is an area of particular concern due to its potential to mislead patients. Banned until 1980, the use of DTC advertising by pharmaceutical companies has increased, though there are guidelines to advertise on television.

Other challenge are the problem of counterfeit drugs. Counterfeit drugs are a growing concern affecting the developed and the developing world. In terms of the risk incurred by companies, a counterfeit drugs distribution under a brand name can have serious effects on the company reputation.

Animal testing is a very vivid debate amongst the pharmaceutical industry, animal welfare NGOs, society at large, and even investors. The topic of testing of drugs on animals is one that the industry has to handle with great care.

Although science and technology have evolved, testing on animals still provides information on how a drug interacts with a living body and is regarded as a critical step, before testing on humans can be carried out. Simulations and alternative technologies do not give all the data necessary to carry the clinical trials further.

Other topics that received significant newspaper coverage are the relation whit the developing countries and efforts to provide access to patients and issues related to vaccines as bird flu.

The cost effectiveness of treatments has become a major issue. In an effort to tackle ever increasing health expenditure, regulatory are increasingly using Health Technology Assessment (HTA) to assess the cost-benefit ratio of treatments and decide whether a drug should or should not be covered by a country health system.

The strong dependence of the industry on decisions from health authorities and government decisions therefore has an impact on pharmaceutical companies. They must demonstrate good behaviour in order to be allowed to market their products, particularly in countries where drugs are covered by publicly financed health insurance.

Corporate Social Responsibility for the European Commission views are "a concept whereby companies integrate social and environmental concerns in their business operations and in their interaction with their stakeholders on a voluntary basis".

Pharmaceutical companies need to take action to address the negative impression about them notwithstanding the tangible commitment they make to healthcare, including R\&D expenditures that represent about 17.7 percent of domestic sales in USA, more than the NIH and the international pharmaceutical industry combined.

The codes for Corporate Social Responsibility need one profound revision.

Overall are business decision- making linked to ethical values, compliance with legal requirements and respect for people, and transparent business practices which will contribute to sustainable business success and, more widely concerns for all stakeholders. CSR goes beyond legal obligations. Appears to be evidence that the 
trust that consumers/patient put in companies is related to the firms behaviour and perceived ethics.

The pharmaceutical industry is, by nature, a sector where the ideas of corporate involvement, responsibility towards patients, ethical behaviour and an overall duty towards society are omnipresent.

The need for R\&D and innovation is great, maybe greater than ever. Populations are rising, and on the whole, aging. People are living longer and rightly expect appropriate care all along their life. Research and development (R\&D) remains a primary necessity in the pharmaceutical sector. The pharmaceutical sector has and feels a responsibility in discovering, developing and delivering medicines and vaccines that can make a difference in people's lives and create a healthier future. There are too a number of issues at stake when it comes to Orphan drugs.

Access to healthcare is a major issue in the pharmaceutical sector. The responsibility of the industry is to work with institutions in order to design schemes that will allow most to access healthcare regardless of their revenues, the country they live in etc. Companies, as part of their CSR activities, need multiplied action by donating medicines to populations in need, by proposing preferential pricing in the world poorest countries in an effort to help fighting diseases such as AIDS and malaria or in supplying vaccines to international NGOs or UN agencies at preferential prices, below those practiced on developed countries.

In Europe, companies focus their sponsorships on humanitarian assistance (HIV/ AIDS, Human Rights, Public Health, Social issues) which culturally is highly valued in corporate philosophy.

Pharmaceutical companies often set up Foundations, in order to support, educate and better address a disease for which they provide treatment. For example a Foundation on diabetes if the company provides insulin treatment; or a Foundation which focuses on AIDS education in Africa for a company providing anti retroviral drugs etc. This effort will be in relation of other privates initiatives as the Bill Gates Foundation.

One way to help the patient/consumer understand the issues the industry faces and reaffirm the industry's contribution to healthcare delivery is by to greater transparency and more willingness to address key issues.

The overriding ethical challenge for the pharmaceutical industry is to serve the well-being of the patient, and then to convince the public that that is precisely what it set out to do. To now the real purpose and objectives of the pharmaceutical industry will be very important for the public and for the industry.

US produces more new drugs "than any other country because it is largely free of price controls ... About 75 percent of all new drugs are discovered and used in the US first". Innovation and patients will get hurt if the emotional appeal for price controls is heeded.

The ultimate ethical goal in the pharmaceutical industry is to discover and develop safe and efficacious drugs that allow patients to live longer, healthier and more 
productive lives, while making a profit to reward shareholders and to invest in research for the next generation of medicines.

The pharmaceutical companies invested more than $\$ 50$ billion over the last 30 years to discover and develop new medicines. Furthermore, studies confirm the inherent risk of those investments.

An encouraging note is the pharmaceutical industry's recognition that general business ethics are critical to its long-term sustainability.

This situation has implications for executives in the pharmaceutical industry. Newspaper and articles coverage is largely negative and highlight the scrutiny placed on pharmaceutical companies.

Pharmaceutical companies are no different from other companies. Could exists conflicts between ethical standards and profits. But the pharmaceutical industry is a sector where any activity that could be detected, suspected or labelled as unethical behaviour is not tolerated by patients, the media and stakeholders at large.

The need for strong and effective corporate governance might be emphasized in the pharmaceutical sector by the fact that pharmaceutical companies, have a strong impact on human health, and are seen as having a "duty" to provide a steady supply of medicines.

Transparency is an attribute that is expected from a pharmaceutical company at every stage of its operations. Transparency is indeed expected in terms of corporate governance, political contributions, lobbying and financial disclosure and executive compensation. This issue is relevant to the pharmaceutical industry in the sense that the worlds top 50 companies are nearly all listed on trade exchanges and therefore, there is a need for transparency from these companies to address the shareholders need for information and maximum return on their investment. The pharmaceutical industry is a long-standing, well structured sector with a strong impact on society in general. It is an industry that is uncompromisingly expected to behave ethically and provide treatments for all. As such, it is under very tight pressures and scrutiny from legislators, NGOs, media and the public at large. It is also a sector that has become very competitive.

Pharmaceutical industry urgently needs to eliminate internal misconduct in some executives and reaffirm before the society his real commitment, as always, for the innovation and the progress of the therapeutic in benefit of the humanity.

Prof. José Luis Valverde Editor in Chief 